\title{
Study on Stadiums and Management System under the Economics Shijun Wang ${ }^{1}$ \\ ${ }^{1}$ Zhenzhou Technical College, Zhenzhou, Henan, 45000 \\ a email
}

Keywords: Stadiums; Reform; Property; Public Goods; Pareto Efficiency

\begin{abstract}
Public sports venues nature of ownership is public ownership, but its offer games, exercise and watch and other service offerings is more close personal belongings, and for the most efficient way of supplying private goods is the introduction of market competition mechanism, it is necessary for our country stadiums career institutional reform. For new major sports venues, from financing, stadium design to the business after the game can be agreed on specific property through different forms of contracts in order to improve the operational efficiency of these venues, increase people's welfare. For those in need of a large number of existing inventory of sports venues (especially sports stadiums foot, basket, volleyball and other projects) resources must start from the league system reform, in order to solve the plight of these venues business fundamentally.
\end{abstract}

\section{Introduction}

Since the construction investment is a major sports venues with a high-risk investment, its long construction period, investment is large, slow recovery of funds, the late management of complex, coupled with the natural aging and overuse bring a higher repair and maintenance costs a series of issues [1], major sports venues construction and operation has become a crucial issue, it is not only directly related to organizing successful large-scale sporting events and failures, but also for the large public stadiums own survival and development is fundamentally influences. Many experts and scholars from different angles on major sports venues, public planning, construction and operation conducted in-depth research, but because of the different research perspectives, ways and means, the resulting conclusions quite different. In this study, the original institutional economics

The Discussion large stadiums are property provided by nature and the nature of the product, and then large stadiums Pareto efficiency at different operation modes of comparative analysis, decision-making consultation and put forward suggestions for the improvement of stadium construction and operation.

\section{The Basic Meaning of Property Rights and Effective Supply of Public Goods Theory}

Problems Of China sports stadium construction and academic research and study business models are all related to the management of institutional issues, in-depth to explore and study the reform of the final properties of the product must be provided to the property and its sports venues and thus bring social and economic benefits and other issues of scientific explanation. To do this, first of all deal with the definition of property rights, public goods and benefits and property rights and sports venues, and the nature of the relationship between the product and other benefits provided were analyzed from the combination of theory and practice.

Property is due to the scarcity of goods between people and cause, associated with its use relationship. This definition of property rights is consistent with the Roman law, common law, economics and political theory of Karl Marx and the new system \# (property) Economics [2]. This definition of property rights bear with two important implications: First, the property rights and human rights in isolation from wrong; thus extended its second meaning, that property is the relationship between people. Cite a simple example: someone got a computer, its ownership is not determined by the relationship between people and computers, but the relationship between people and the rights of others on the use of computers. The so-called property rights, it is through a series of legal provisions on the protection of the Code of Conduct and the economic and other related 
items made provision for all items with other people must be strictly observed in their interactions, or they will have to bear the incurred the penalty cost. This means that ownership is the core concept of property rights, a complete title contains the following four aspects: (1) the right to use that right to use the asset; (2) usufruct, namely the right to the proceeds of assets; (3 ) right to dispose of assets that is changing the form and substance of the claim; (4) the transfer of the right to push the two sides agreed price to transfer all or part of the rights of the three provisions to the rights of others.

Public goods (public goods) theory is the basis of Public Service Supply Mode. Before the mid-1950s, whether it is politics, management and economics for the normative study of public goods is relatively weak. Until 1954 and \# 1955, Paul Samuelson (Paul. A. Samuelson) published his famous essay two, fishes defined public goods, the best allocation of resources needed for the production and government tax system design and other key questions with corresponding answers.

Sabouraud definition of public goods are those items at the same time having a non-exclusive and non-competitive. The so-called exclusivity refers to those who have enough to complete the exclusive property of the article, it has the absolute right of disposal, and can effectively exclude others from the possession of the goods. The so-called competitive means some increase consumer goods, will cause an increase in the marginal cost. Here, it is determined whether to increase the marginal cost of the standard contains two aspects: First, production will need to invest additional resources; the second is whether consumption will lead to quality and quantity diminishes, that will bring congestion costs (congestioncost ). Clearly, private goods and public goods that is opposite meanings, both exclusive and competitive products. Practice and the fact that our country from a planned economy to a socialist market economy has proved that the market competition mechanism to meet the personal needs of the most efficient products and energy resource allocation means.

1954 Sabouraud proposed Samuelson model and deduce the conditions for the effective provision of pure public goods (that is, the Samuelson condition): In general, as long as the existence of private and public goods economy, the pure the best configuration conditions of public goods is its marginal rate of substitution equals marginal rate ${ }^{1}$. That is, only when all members of society to obtain benefits from the production of public goods is equal to the opportunity cost of public goods objective takes, the supply of pure public goods is the most efficient, optimal. In reality, a large society, because no matter what kind of government there are two basic problems difficult to solve using: First, provide a mechanism for gathering citizen aspirations; second is to promote citizens faithfully express their wishes, therefore, pure public goods supply the needs of government aid in the form of tax implementation.

\section{Public Nature of the Property and Provide Stadiums Nature of Products}

A country and cities hosting major sporting events, on the one hand, there are social and political objectives and to promote its intentions (such as increased national and international prestige and social awareness in the region and expand its social impact, strengthen the extensive social exchanges, etc.); on the other hand, it can also promote the economic development of the country and local, municipal construction and improvement of sports facilities, provide impetus for sustainable growth and social development. Therefore, many countries and regions according to their economic and social development, national and local economic strength and taxes for the protection, use of modern media technologies (sports media media), these major sporting events as a public offer to hold free the people of the country, at this time, large public stadiums to provide large-scale sporting events such public goods essential support and tools.

Construction investment in stadiums is a high risk of investment because of its long construction period, large amount of investment, high professional requirements, the slow recovery of funds, management of late complex series of problems at home and abroad for large sports venues to be built in all

On the right are generally used in the form of public ownership ${ }^{\circ}$. Even in Europe and the United States and other Western capitalist countries, many cities its location to participate in the four major league clubs, are mostly used by local government tax funds and issuance of local bonds to build 
stadiums, and by the professional club management, but the property is still owned by the local government. Although China's social system is different from the Western capitalist countries, but sports venue construction investment and the property has been in the form of public ownership of the state and local government investment, with the deepening of reform and opening up, although in recent years voted for stadiums aspects, and financing system, etc. carried out some reforms, but the nature of their ownership - public property has not changed.

Although large-scale sporting events through modern media technology to provide public goods are mostly, but not equal to the stadium itself is the product offering public goods. According to an exclusive and competitive analysis, as stadiums / public facilities in fact is not necessarily complete / public good economic sense: because the stadium sports venues and audience seats are limited, some people in the game there, exercise, enjoy event, while the other part can not be there in the game, exercise, watching the competition, therefore, has / competitive. Meanwhile, the stadium / exclusivity in transport costs implicit exclusive role is also reflected, moreover, stadiums to achieve / exclusive nor is there any technical difficulties, the ticket can be. Visible, sports venues to provide services and products closer to personal items [4].

\section{Large Public Stadiums under Construction}

Large sports economy is a special economic phenomenon, characterized by its very nature is a kind of attention in terms of economy, it is in a particular region, a particular time in the huge crowd carried, capital flow, information flow of the three streams sport, so there are some limitations. From an economic point of view, large sports venues instantaneous flow must determine its massive athletics stadium, and because the cost of the indivisibility of the game may not bring economies of scale.

According to an exclusive and competitive analysis, stadium provided services and products closer to personal belongings and personal items in the field, the market is no doubt that government efficiency. For a long time, China's public facilities from design to construction, from investment to the operator, are all monopolized by the government. As a result, often neither economic, social is also poor. In general, the design and construction of large-scale events stadiums often act according to the will of the organizing committee, and / committee important consideration is often the effect of events, for return on investment, after the game operators will attend. After the dissolution of the race organizing committee, will be forwarded to the relevant departments stadiums (such as sports bureau, etc.), except for the lack of incentive and restraint mechanisms, but also constrained by inadequate design of the venues and working capital and other factors, coupled with mismanagement, poor management, etc. reason, the results of a considerable number of venues after several years of wind and rain wash, hard, year after year dilapidated eventually become a heavy financial burden. In view of this, the 2008 Beijing Olympic Games Organizing Committee bold and innovative system of property rights, property rights and other new take BOT mode, use the right way by the use of private capital investment in competitive sports venues for some time, and the right to dispose of usufruct part of the facility, without changing the nature of ownership of state-owned stadiums obtained on the basis of the Government's financial investment outside, and as a corporate private capital in the construction of venues designed to generally consider the use of function after the game, both profit targets in the investment, operating will also follow the laws of the market, it goes without saying that the economic and social benefits.

In both the efficiency and fairness of the selection, the academic formation of two sharply opposing views: some scholars from the perspective of equity, emphasizing the stadiums are property-public nature of the case, therefore, must be operated by the institutions responsible, and to the free citizens provision of public goods; another part of the scholars from the viewpoint of improving efficiency, emphasizing the large stadiums belong to operating assets, should focus on profit objectives, the business unit type past restructuring for profit enterprises. To facilitate the discussion, the author and from the perspective of a fair selection of operating mode called / career mode, benefit from the perspective of the selected mode of operation is called mode of operation, expand the following Discrimination. 
Select career mode operating mode, only the theoretically determined from the non-exclusive right to use the stadium, but can not solve the stadium problem of providing competitive products, and the fact that the presence of the previously mentioned exclusive hidden problems, which no species exclusive surface but there is resource development while competitive, the result will inevitably lead to the tragedy of the commons. In the course of this operation mode, the people on the one hand as a taxpayer to pay for the construction of sports venues; on the other hand, must also be a huge stadium maintenance and repair costs of late payments. Obviously, stadiums press career mode operation is not Pareto optimal.

With the deepening of reform, the management system of public sports venues by the specific program management through budget management (full management, balance management) y lease contract responsibility system and a series of evolution, the progressive realization of the executive management to type operation management of the transition. Select this model will be part of the administrative staff peeled, be transformed into enterprises, rely on market-oriented operation of the self-financing, mainly from the stadium property ownership sector perspective on business scope, facility maintenance, distribution and disposal of usufruct rights issues by contract forms and conventions to regulate the venue management business. Obviously, this model is not only beneficial to reduce the burden on state or local finances, that the burden on taxpayers, but also to meet the needs of some consumers, with respect to the business model, is undoubtedly one kind of reform toward Pareto optimal development. However, this theoretical analysis will be linked to the practice of sport management and reform in our stadium, we can not evade this business model reform there are some limitations (mainly due to sport-specific). From the current preliminary practice of reform, the business model is more suitable for consumer-related entertainment and leisure projects, such as table tennis, badminton, swimming, etc., but for some large projects (such as football, basketball, volleyball, three balls, as well as track and field and other projects ) stadium management, the effect is not obvious. From our preliminary survey, a large number of sports venues using / business model into a vice support body dilemma, some even contrary to the right to dispose of the contract agreement, changing facilities and stadiums use a long time in concert will, trade fairs and job fairs and other means as their main business.

\section{Conclusion}

Public sports venues nature of ownership is public ownership, but it provides competition, exercise and watch and other service offerings is more close personal belongings. Since the introduction of market competition mechanism is the most efficient form of organization of production of private goods, it is essential to our current stadium business career institutional reform. For new major sports venues, from financing, stadium design to the business after the game can be agreed on specific property through different forms of contracts in order to improve efficiency in the use of these venues, increase the welfare of the people. And for those in urgent need to revitalize the existing sports venues (stadiums in particular foot, basket, volleyball, track and field events, etc.) resources must start from the league system reform, in order to solve the plight of these venues business fundamentally.

\section{Acknowledgements}

This is the initial results in 2014 of Henan Province Science and Technology Department of soft science and technology projects. Project Fund Number: 142400411303

\section{References}

[1] Tang Qiyu, Yang Sitong.. Large Sports Venues after business use Probe [J]. Shandong Institute of Physical Education, 2004, (3).

[2] Svetozar Pejovich property economics [M]. Beijing: Economic Science Press, 1999.

[3] Ansel M. Sharp, economics and other social issues (Fifteenth Edition) [M]. Beijing: China 
Renmin University Press, 2003.

[4] Wang Xueshi, Guo Huiping. Consideration of the 2008 Beijing Olympic venues, business strategy management [J]. Sports Management, 2005, (2).

[5] Zhang Yan. nature of public sports venues Analysis of [J]. Sports and Science, 2004, (3).

[6] Guo Huiping, et al. Diagnosis and Countermeasures public stadium business management issues [J]. Wuhan Institute of Physical Education, 2005, (8).

[7], Linxian Peng, Liu Yunfa. Made foreign community sports center construction and management studies [J]. Sports Science, 2005, (12). 